\title{
A new model for university-industry links in knowledge-based economies
}

\author{
Petra Ahrweiler, Andreas Pyka and Nigel Gilbert
}

\begin{abstract}
In this paper, we apply the agent-based SKIN model (Simulating Knowledge Dynamics in Innovation Networks) to university-industry links. The model builds on empirical research about innovation networks in knowledge-intensive industries with procedures relying on theoretical frameworks of innovation economics and economic sociology. Our experiments compare innovation networks with and without university agents. Results show that having universities in the co-operating population of actors raises the competence level of the whole population, increases the variety of knowledge among the firms, and increases innovation diffusion in terms of quantity and speed. Furthermore, firms interacting with universities are more attractive for other firms when new partnerships are considered. These results can be validated against empirical findings. The simulation confirms that university-industry links improve the conditions for innovation diffusion and enhance collaborative arrangements in innovation networks.
\end{abstract}

\section{Introduction}

$R \& D$ and industrial policy assume that university-industry links are the fuel of knowledgebased economies (Dasgupta and Stoneman 1987). Universities are supposed to serve a "third mission" in contributing to economic development (e.g. Lee 1996, Meyer-Krahmer and Schmoch 1998, Etzkowitz 2002, Agrawal and Henderson 2002, Schartinger et al. 2002, D'Este and Patel 2007). There is a huge body of empirical research on the possible ties between universities and firms - be they formal (contract research, joint supervision of masters and PhD students, licensing of university patents to companies, co-publications, copatenting, purchasing of university-developed prototypes, contract consulting, formation of entrepreneurial university spin-offs, university-based training and professional development for firm employees, use of university libraries, laboratories and other facilities by firms, employment of graduates by companies, joint research programmes, and mutual secondments, as well as collaborative R\&D) or informal (meetings, email communication, jointly attended lectures and conferences). Universities are expected to provide the permanent enlargement and diversification of the industrial knowledge base that underpins innovation. Furthermore, universities are considered to be "stable" and reliable network partners because of their public funding and inertia against market turbulence. Public spending on university-industry collaborations is therefore considerable.

Policymakers (and the public) expect that current investments in academic research and university-industry networks will produce a flow of new and innovative products and processes with high commercial returns in science-based firms and a positive impact on labour markets. However, empirical evidence demonstrating the direct commercial profitability of the "science connection" is scarce.

In October 2007, a paper was presented at the Meeting of the Statistical and Social Inquiry Society of Ireland titled "Is Irish Innovation Policy Working? Evidence from Irish High- 
Technology Businesses" (Jordan and O'Leary 2007). Based on a survey of mainly biotech and ICT businesses in 2004, it studied the relationships between Irish universities and Irish hightech firms, and the firms' innovation performance. An econometric model was used to explore whether companies interacting with the higher education sector had a higher or lower number of product and process innovations (as compared to other enterprises). The frequency of interaction of firms with different innovation partners - among them customers, suppliers, competitors, development agencies and universities - was measured on a five-point scale. The results indicated that companies co-operating with universities showed significantly lower growth rates than companies with no link to science at all. From this, the authors concluded that the interaction of enterprises with universities is negatively associated with product and process innovation. They said that the innovation output of Irish businesses may be negatively affected and that future national prosperity may be undermined by continued investment in university research and university-industry collaboration. The resolution of the paper was that attempts to build local linkages and clusters were a wasted effort ${ }^{1}$.

We could dismiss this study as an example of drawing extreme policy conclusions on the basis of an over-simplified econometric model of the innovation process. However, this is not the only empirical study finding evidence for the apparently constraining effect of university affiliation. As Castells (1994) showed in his analysis of technopoles of the world: attachment to academia does not lead automatically to a high innovation performance. However, the causal relationship may not be the obvious one. There is a tendency for university spin-offs to be lacking in business skills and commercial capabilities (Meyer 2003; Shrader and Siegel 2007). These firms seem to be less profit-oriented and less engaged with growth strategies than firms without university affiliation.

Although there are counter-studies with the opposite results for firms with and without university connection (e.g. George et al. 2002), much empirical evidence and support for the beneficial effects of university spin-off activity (cf. O'Shea, Chugh and Allen 2008; Wright et al. 2006), and analyses of the economic phenomena following "entrepreneurial universities" and "academic capitalism" (Etzkowitz 2004; Slaughter and Leslie 1999) providing empirical evidence for the benefits of university-industry links, studies such as the Jordan and O'Leary paper always find an interested audience, both inside and outside academia. For instance, it has been argued that "technology-intensive firms are beginning to worry aloud that increased industrial support for research is disrupting, distorting, and damaging the underlying educational and research missions of the university, retarding advances in basic science that underlie these firms' long-term future" (Florida 2000: 367).

This paper introduces an agent-based simulation to investigate the role of university-industry links for innovation generation and diffusion in networks. Innovation diffusion in networks is a highly attractive research topic for innovation economics and a design target for R\&D policy considering profitable returns from knowledge investments. However, since innovation networks show highly complex micro dynamics, there is no linear and immediate relationship

\footnotetext{
${ }^{1}$ This policy conclusion was met with fascination in the Irish media (e.g. article "Innovation is not academic", Irish Times, $14^{\text {th }}$ of January 2008, http://www.irishtimes.com/newspaper/innovation/2008/0114/1199917908535.html) and by Irish policymakers (e.g. article "Research spending is key to success", Irish Times, 22/05/08 http://www.irishtimes.com/newspaper/sciencetoday/2008/0522/1211370778915.html).
} 
between increased knowledge inputs and economic profits. We have to understand the micro dynamics at the actor level to learn about potential access points for policy intervention and support.

\section{The role of knowledge and innovation for the economy}

In economic theory, innovation diffusion has often been described in terms of 'technological spillovers'. This concept is borrowed from macro-economics, where spillovers are the engine of economic growth due to the positive feedbacks they induce in economic development (e.g. Romer 1990). In micro- and industrial economics the concept of technological spillovers was carried over by referring to the public good nature of new technological knowledge. Accordingly, in the incentive-based approaches of neoclassical industrial economics, technological spillovers are considered as involuntary knowledge flows that reduce the incentive to be engaged in costly R\&D. However, the negative interpretation of technological spillovers has had an impact on the assessment of collaborations in industrial R\&D.

In the early theories of industrial organisation, collaborative R\&D was considered to be only a temporary phenomenon (e.g. Harrigan 1985, Sapienza 1989). Additionally, on the basis of well-established anti-trust principles, collaborative agreements were supposed to be suspicious. For example, in transaction costs theory, innovation networks were taken as a hybrid form of industrial organisation, between hierarchy and markets, that eventually will disappear. The developments in the biotechnology-based industries were cited as examples, where since the late 1980s well established pharmaceutical firms have frequently been engaged in co-operative research with specialised biotech start-up companies (e.g. Pyka and Saviotti 2005, Ahrweiler, Gilbert and Pyka 2006). These collaborations were supposed to allow access to the upcoming biotechnology paradigm for the established pharmaceutical firms, which had previously specialised in organic chemistry. The collaborations were then expected to dissolve: either the large pharmaceutical firms would build up their own competence in biotechnologies (including through the acquisition of biotech start-ups) and therefore no longer need collaboration partners, or the biotech start-ups would displace the large pharmaceutical firms and become the dominant actors in the pharmaceutical industries themselves. From this perspective, long-lasting collaborations are anomalous and knowledge flows between firms (i.e. technological spillovers) are implicitly considered to have negative effects on the level of R\&D investment.

Neither of these two alternatives has transpired. In the early years of the 21st century both the large pharmaceutical firms and the small biotech firms co-exist while innovation networks still shape the industrial organisation of R\&D processes in this industry. Meanwhile, in the literature of Organizational Learning the term liability of disconnectedness' has been used to describe the importance for industrial actors of getting access to external knowledge sources via collaboration (Powell et al. 2005).

The lack of interest until the end of the 1980s in R\&D collaborations in the theory of Industrial Organization can be traced back to a negative view of technological spillovers characteristic of neo-classical industrial economics. Technological spillovers were considered to reduce R\&D incentives (e.g. Levin and Reiss, 1988) and therefore detrimental for economic welfare. At end of the 1980s this view changed and R\&D collaborations slowly moved to the centre of interest. In 1988, D'Aspremont and Jacquemin showed that cooperation in R\&D can lead to higher R\&D intensity when there is a high degree of 
technological spillover. Cohen and Levinthal (1989) introduced the concept of absorptive capacity, which firms need in order to benefit from technological spillovers.

The multifaceted nature of new technological knowledge gradually moved to the centre of interest, challenging the idea of it being a public good. Knowledge was characterised as tacit (Polanyi 1967), local (Atkinson and Stiglitz 1969), cumulative (Cowan et al. 2000) and complex (Malerba and Orsenigo 1993). Accordingly, technological spillovers are likely to support industrial innovation processes by spurring the collective innovation processes and allowing for the exploration of extensive technological opportunities (Coombs 1988), whereas the incentive-reducing effects are relevant only for a small fraction affecting the intensive technological opportunities (Coombs 1988) within a single industry. Referring to this important discussion, Nelson (1989) coined the notion of knowledge being only a 'latent public good'. Appropriability conditions are far better than the traditional view on new technological knowledge suggests and accordingly the incentives to undertake R\&D are far less endangered by technological spillovers.

This switch from the 'incentive-based' to the 'knowledge-based' view of the nature of industrial R\&D also has consequences for the idea of considering technological spillovers as involuntary knowledge flows. Geroski (1995: 85) stressed this point: "In particular, what often appears to be an involuntary flow of knowledge between firms may be nothing more than a pair of draws from a narrow but common pool shared by a group of agents within a common set of problems." In other words, firms may have to take positive action to make their newly developed knowledge available to others (Nelson 1988) in order to spur the collective innovation process. Technological spillovers have to be embedded in the innovation networks that bind collaborative R\&D projects between the different actors in an industry. In this light, the traditional discussion of technological spillovers and their impact on the behaviour of firms and on industrial dynamics is misleading without considering innovation networks as a means for innovation diffusion.

The emphasis on knowledge collaboration and innovation networks first became central in a new strand of literature, namely Industrial Dynamics in a Neo-Schumpeterian tradition (Hanusch and Pyka 2007). In Industrial Dynamics, instead of the incentive reducing effects of spillovers, their knowledge creating effects are heavily emphasised (see e.g. Cantner and Pyka 1998; Eliasson 1995); and these have to be considered as the basic motive for industrial actors to engage in collaborative R\&D. To analyse the impact of these mutual knowledge flows in industrial learning processes, the traditional modelling framework with its strong assumptions, in particular the equilibrium orientation and the presumption of perfect rationality, is not applicable. Instead, to capture the dynamics of industrial learning processes fed by heterogeneous actors, numerical simulations are adopted (see e.g. Windrum 2007).

Since innovation networks consist of many heterogeneous actors following diverse rule sets located in a large parameter space of environmental conditions, there is a need to capture the non-linear dynamics in a model and to experiment with it. Only then is it possible to understand what is happening and what can happen on the macro level, i.e. to assist decisionmakers with evidence-based policy strategies. Over the last few years, the methodology of agent-based modelling (ABM) (Gilbert and Troitzsch 2005; Gilbert 2007; Tesfatsion 2001) has frequently been adopted. Using agent-based simulation informed by empirical research allows us to set up artificial "innovation networks" and to experiment with them to find out what emerges from their dynamics. 
Combining agent-based simulation and empirical research, we will show whether and how the extension of industry-industry networks in knowledge-intensive sectors by university-industry linkages will indeed encourage innovation performance and diffusion. This will be done by building on the existing SKIN model (Pyka, Gilbert and Ahrweiler 2007), which focuses on the simulation of knowledge dynamics in self-organising innovation networks, and on insights from our current EU project NEMO (Network Models, Governance, and R\&D Collaboration Networks), which provide the material for the required extensions.

\section{Agent-based simulation with SKIN}

In this paper, we model the networking behaviour of innovative actors focussing on universityindustry links and analysing their contributions by building on prior work (e.g. Gilbert, Ahrweiler and Pyka 2007) with the SKIN simulation. SKIN is a multi-agent model of innovation networks in knowledge-intensive industries grounded in empirical research and theoretical frameworks from innovation economics and economic sociology. The agents represent innovative firms who try to sell their innovations to other agents and end users but who also have to buy raw materials or more sophisticated inputs from other agents (or material suppliers) in order to produce their outputs. This basic model of a market is extended with a representation of the knowledge dynamics in and between the firms. Each firm tries to improve its innovation performance and its sales by improving its knowledge base through adaptation to user needs, incremental or radical learning, and co-operation and networking with other agents. This section will describe the elements and processes of this model (Gilbert, Ahrweiler and Pyka 2007; Pyka, Gilbert and Ahrweiler 2007). The SKIN model is the result of a number of projects that combined empirical research into innovation networks with agentbased simulation.

The work started with the EU project "Simulating self-organising Innovation Networks" (SEIN). This project combined five empirical case studies in different sectors of technological innovation and in different EU member states with agent-based simulation of these case studies. The results of the SEIN project are summarised in Pyka and Kueppers (2003). Case studies described knowledge-intensive European industry sectors such as the biotechnologybased pharmaceutical industry in France (Pyka and Saviotti 2003), combined heat and power technology networks in The Netherlands, Germany and the UK (Weber 2003), knowledgeintensive business services in the UK web design industry (Windrum 2003), and the UK Virtual Centre of Excellence in the European telecommunication industry (Vaux and Gilbert 2003). The task of the SEIN project was threefold: theory formation, empirical case studies, and agent-based simulation. The objective was to derive a theory of innovation networks from insights derived inductively from the case studies and to implement this theory of innovation networks into an agent-based model $^{2}$. The result of the modelling activities was an agent-based model - grounded in empirical research and informed by empirical data coming from the case studies (Gilbert, Pyka and Ahrweiler 2003). The model was used by the European Commission for scenario modelling of current and future innovation policy strategies (Ahrweiler, de Young and Windrum 2003) referring to the technological sectors and EU Member States of the case studies.

\footnotetext{
${ }^{2}$ Since empirical research is embedded in theoretical frameworks itself, this actually meant a close interaction of theoretical frameworks and empirical research from the outset of the project. The case study partners provided theoretical contributions from Neo-Schumpeterian Economics, Economic Sociology, Organisational Learning etc. to guide empirical research in case studies.
} 
The current SKIN model builds on the procedures we implemented for the biotechnologybased pharmaceutical industry in Europe using this sector as an example par excellence of a knowledge-intensive industry. Therefore, when showing in more detail how the model procedures are rooted in empirical research, we will focus on this industrial sector specifically. Empirical research for refining the SKIN procedures has been conducted in the bi-national research project of the British Research Council and the German DAAD "Comparing German and UK biotechnology-based pharmaceuticals: Simulating Knowledge Dynamics in Innovation Networks" (SKIN). The empirical work is summarised in Ahrweiler, Gilbert and Pyka (2006).

\subsection{The model}

A core concept of a model on innovation networks is knowledge. Accordingly, one of the first modelling tasks is to find an appropriate knowledge representation. The approach to knowledge representation used in our model is similar to Toulmin's (1967) evolutionary model of knowledge production. This identified concepts, beliefs and interpretations as the "genes" of scientific/technological development evolving over time in processes of selection, variation and retention. Ackermann (1970) interpreted the works of Kuhn and Popper according to this perspective allowing for different selection systems. In the SKIN model the "kene" is used to represent the aggregate knowledge of an organisation (Gilbert 1997).

\subsubsection{The agents}

The individual knowledge base of a SKIN agent, its kene, contains a number of "units of knowledge". In the artificial space of a model, kenes could consist of arbitrary bit sequences of indefinite length. However, we need to portray the knowledge of our artificial agents in a way which allows comparison with empirical actors. Therefore, the composition of kenes is inspired by the well-known International Patent Classification (IPC) of patent offices. The IPC provides a hierarchical system of language-independent symbols for the classification of patents according to the different areas of technology to which they apply. IPC Codes of patents allow the assignment of technological fields and competences with so-called concordance tables (cf. Schmoch et al. 2003) to identify industrial sectors. In this sense, the IPC Codes can be considered as coordinates of an empirical knowledge space and correspond approximately to the "units of knowledge" in the kenes of our model ${ }^{3}$.

Each unit in a kene is represented as a triple consisting of a firm's capability $C$ in a scientific, technological or business domain, its ability A to perform a certain application in this field, and the expertise level $E$ the firm has achieved with respect to this ability (see figure 1 ). The kene's capabilities C correspond to the 3-digit IPC Codes, which represent broad technological fields, e.g. the code $\mathrm{C07}$ stands for organic chemistry. One level below, on the 4-digit level, we find the various occurrences within the capabilities domain, which correspond to the abilities A, e.g. the code C07K represents all technologies related to processes of preparation of peptides. As every capability $\mathrm{C}$ has many (in principle infinite)

\footnotetext{
${ }^{3}$ The analogy is not exact, for the kene units can represent items of tacit knowledge (which can therefore not be made explicit as IPC codes) and can also represent non-technical knowledge, such as business strategies, marketing techniques and management competences, none of which are patentable.
} 
occurrences (abilities A), each 3-digit IPC Code has several specifications on the 4-digit level, and these can be augmented if new, so far non-classified technologies become available.

For almost every technological artefact or process, many capabilities - as well as different abilities within one capability domain - need to be applied (so-called combinatorial technologies, cf. Teece 1987). Therefore patents generally list several IPC codes. In our model a firm's kene is a collection of C/A/E-triples, of variable number and representing its artificial knowledge space. The units of knowledge in the kene are used in a combinatorial way to produce innovations.

$$
\left\{\begin{array}{l}
C \\
A \\
E
\end{array}\right\},\left\{\begin{array}{l}
C \\
A \\
E
\end{array}\right\},\left\{\begin{array}{l}
C \\
A \\
E
\end{array}\right\},\left\{\begin{array}{l}
C \\
A \\
E
\end{array}\right\},\left\{\begin{array}{l}
C \\
A \\
E
\end{array}\right\}, \ldots
$$

Fig. 1: The kene of an agent

In much the same way as the empirical knowledge base of a firm can be described by drawing on the IPC Codes from its patents, the units of knowledge in the kenes of our artificial agents can be used to describe their virtual knowledge bases. The patent documents list all IPC Codes that are relevant to the patented technology. This list of IPC Codes can be therefore considered as a description of the capabilities and abilities necessary to master a certain technology. Pyka and Hörlesberger (2004) use the IPC Codes of the patents of a firm to visualise its knowledge base. They assume that the expertise of a firm in a certain technological ability is high if the respective 4-digit IPC Code is found frequently in the patents of the firm. In the graphical representation shown in fig. 2, 4-digits IPC Codes are represented as circles whose size is dependent on this frequency, i.e. the more often the IPC Code can be found, the better developed are the respective abilities and the larger is the circle. This corresponds to the expertise level $\mathrm{E}$ of one unit of a kene.

The positions of the abilities in the 2-dimensional knowledge map depend on the coordinates given by the IPC Codes. Additionally, technologically related technologies attract each other and therefore are moved together more closely in the knowledge map. Pyka and Hörlesberger (2004) consider the co-occurrences of IPC Codes to represent technological relatedness. The more often two IPC Codes are used together in a single patent, the better connected are the respective technologies. In the knowledge maps, these abilities are moved together and connected with a line.

Figure 2 describes the knowledge base of the French pharmaceutical company RhonePoulenc on the basis of all its 1266 patents filed at the European Patent Office (EPO) from 1995 to 1999. The largest circle in the centre (a61k), for example, stands for "preparations for medical purposes", which obviously is a core competence of a pharmaceutical company. The colour-shaded abilities belong to the domain $\mathrm{c} 12$, which is biochemistry. Accordingly, the knowledge map shows that in the mid 1990s Rhone-Poulenc started to integrate molecular biology into their core competences as these abilities are well connected to the traditional pharmaceutical technologies. 


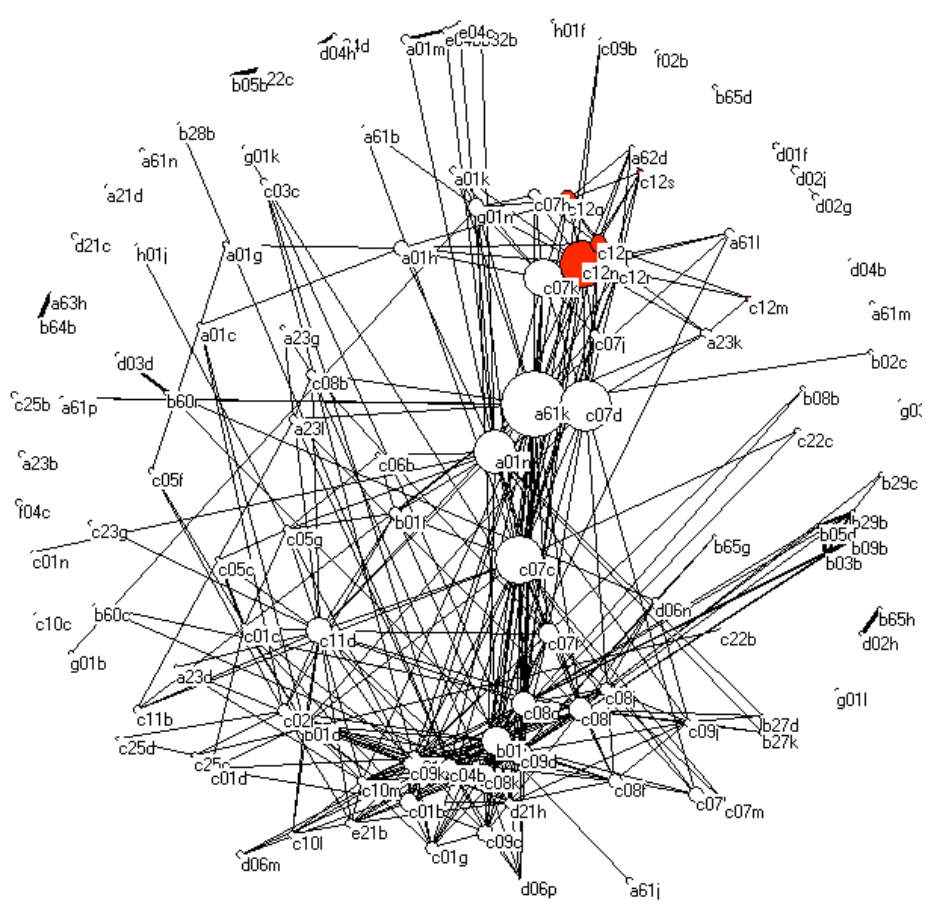

Fig. 2: Knowledgebase of Rhone-Poulenc (1995-1999); source: EPO PATSTAT

\subsubsection{The market}

Because actors in empirical innovation networks of knowledge-intensive industries interact on both the knowledge and the market levels (cf. Garcia et al. forthcoming b: 2), we need a representation of market dynamics in the SKIN model. Agents are therefore characterised by their capital stock. Each firm, when it is set up, has a stock of initial capital. It needs this capital to produce for the market and to finance its R\&D expenditures; it can increase its capital by selling products. The amount of capital owned by a firm is used as a measure of its size and additionally influences the amount of knowledge (measured by the number of triples in its kene) that it can maintain. In many knowledge-intensive industries we find a coexistence between large and small actors (e.g. the large pharmaceutical firms and the biotech start-ups, and the former national monopolists and high technology specialists in the ICT industries, cf. Pyka and Saviotti 2005). We assume that large diversified firms are characterised by a larger knowledge base as compared with smaller specialised companies (cf. Brusoni et al. 2001). Most firms are initially given the same starting capital allocation, but in order to model differences in firm size, a few randomly chosen firms can be allocated extra capital.

Firms apply their knowledge to create innovative products that have a chance of being successful in the market. "Most technology is specific, complex... (and) cumulative in its development... It is specific to firms where most technological activity is carried out, and it is specific to products and processes, since most of the expenditures is not on research, but on development and production engineering, after which knowledge is also accumulated through experience in production and use on what has come to be known as "learning-by doing" and "learning-by-using"" (Pavitt 1987: 9). The special focus of a firm, its potential innovation, is called an innovation hypothesis. In the model, the innovation hypothesis $(\mathrm{IH})$ is derived from a subset of the firm's kene triples. 
The underlying idea for an innovation, modelled by the innovation hypothesis, is the source an agent uses for its attempts to make profits in the market. Because of the fundamental uncertainty of innovation (Knight 1921), there is no simple relationship between the innovation hypothesis and product development. To represent this uncertainty, we developed the following mechanism: the innovation hypothesis is transformed into a product through a mapping procedure where the capabilities of the innovation hypothesis are used to compute an index number that represents the product. The particular transformation procedure applied allows the same product to result from different kenes, which is not too far from reality where the production technologies of firms within a single industry can vary considerably (Winter 1984).

A firm's product, $\mathrm{P}$, is generated from its innovation hypothesis as

$$
P=\left(\sum_{I H} C_{i}\right) \bmod N
$$

(where $\mathrm{N}$ is a large constant and represents the notional total number of possible different products that could be present in the market).

A product has a certain quality, which is also computed from the innovation hypothesis in a similar way, by multiplying the abilities and the expertise levels for each triple in the innovation hypothesis and normalising the result. Whereas the abilities used to design a product can be used as a proxy for its product characteristics, the expertise of the applied abilities is an indicator of the potential product quality. In order to realise the product, the agent needs some materials. These can either come from outside the sector ("raw materials") or from other firms, which generated them as their products. Which materials are needed is again determined by the underlying innovation hypothesis: the kind of material required for an input is obtained by selecting subsets from the innovation hypotheses and applying the standard mapping function (equation 1 ).

These inputs are chosen so that each is different and differs from the firm's own product. In order to be able to engage in production, all the inputs need to be obtainable on the market, i.e. provided by other firms or available as raw materials. If the inputs are not available, the firm is not able to produce and has to give up this attempt to innovate. If there is more than one supplier for a certain input, the agent will choose the one at the cheapest price and, if there are several similar offers, the one with the highest quality.

If the firm can go into production, it has to find a price for its product, taking into account the input prices it is paying and a possible profit margin. While the simulation starts with product prices set at random, as the simulation proceeds a price adjustment mechanism following a standard mark-up pricing model increases the selling price if there is much demand, and reduces it (but no lower than the total cost of production) if there are no customers. Some products are considered to be destined for the 'end-user' and are sold to customers outside the sector: there is always a demand for such end-user products provided that they are offered at or below a fixed end-user price. A firm buys the requested inputs from its suppliers using its capital to do so, produces its output and puts it on the market for 
others to purchase. Using the price adjustment mechanism, agents are able to adapt their prices to demand and in doing so learn by feedback.

In making a product, an agent applies the knowledge in its innovation hypothesis and this increases its expertise in this area. This is the way that learning by doing/using is modelled. The expertise levels of the triples in the innovation hypothesis are increased and the expertise levels of the other triples are decremented. Expertise in unused triples in the kene is eventually lost and the triples are then deleted from the kene; the corresponding abilities are "forgotten" or "dismissed" (cf. e.g. Hedberg 1981).

Thus, in trying to be successful on the market, firms are dependent on their innovation hypothesis, i.e. on their kene. If a product does not meet any demand, the firm has to adapt its knowledge in order to produce something else for which there are customers (cf. e.g. Duncan 1974). A firm has several ways of improving its performance, either alone or in cooperation, and in either an incremental or a more radical fashion.

\subsubsection{Learning and co-operation: improving innovation performance}

In an earlier publication (Gilbert, Ahrweiler and Pyka 2007), we showed how these learning features of the SKIN model are theoretically grounded in the body of literature known as "Organizational Learning" (OL). After John Dewey introduced the concept of experiential learning as a permanent activity cycle (Dewey 1938) and started a discussion among educationalists about feedback learning and learning by doing, Donald Michael coined the term, organisational learning (Michael 1973). Argyris and Schön's influential monograph, "Organizational Learning" (1978; newly edited including further work as "Organizational Learning II", 1996) proposed that a learning organisation is one that is permanently changing its interpretation of the environment. In doing so, the organisation learns new things and forgets old ones. Drawing on their background as action theorists, Argyris and Schön show how these interpretations are gained and how they are connected to different organisational behaviours. They distinguish between three types of learning, rooting them in an understanding of organisational agency that targets growth and effectiveness:

- Single-loop learning: This is adjustment learning, referring to the rational use of one's own means and instruments to adapt to environmental requirements, given a set of organisational goals, strategies and behaviours. It targets an improvement of the "theory in use" of an organisation using a simple action-outcome feedback and follows the heuristic, "maximise gains and minimise loss".

- Double-loop learning: This is turnover learning with respect to the meta-level of goals, strategies, and behaviours of an organisation, and aims to adapt them to environmental requirements. The learning process includes un-learning of redundant knowledge to clear space for new behaviours. Furthermore, co-operation, including assumption and benefit sharing with collaborators, is seen as a vehicle for learning.

- Deutero learning: This is meta-level learning of the highest order where the organisation reflects on its own identity. Here, the learning process itself is the object of learning ("to learn how to learn"). The organisation's norms and values are subject to critique and change.

The SKIN model takes many of the ideas of the Argyris and Schön framework and uses them to examine the assumption that, in the words of de Geus (1997), the greatest competitive advantage for any firm is its ability to learn. Experiments concerning the effects of different 
combinations of learning activities on the agent population are reported in Gilbert, Ahrweiler and Pyka (2007). In the SKIN model, firms may engage in single- and double-loop learning activities. Firm agents can:

- use their capabilities (learning by doing/using) and learn to estimate their success via feedback from markets and clients (learning by feedback) as already mentioned above and/or

- improve their own knowledge incrementally when the feedback is not satisfactory in order to adapt to changing technological and/or economic standards (adaptation learning, incremental learning).

If a firm's previous innovation has been successful, i.e. it has found buyers, the firm will continue selling the same product in the next round, possibly at a different price depending on the demand it has experienced. However, if there were no sales, it considers that it is time for change. If the firm still has enough capital, it will carry out "incremental" research (R\&D in the firm's labs). Performing incremental research (cf. Cohen and Levinthal 1989) means that a firm tries to improve its product by altering one of the abilities chosen from the triples in its innovation hypothesis, while sticking to its focal capabilities. The ability in each triple is considered to be a point in the respective capability's action space. To move in the action space means to go up or down by an increment, thus allowing for two possible "research directions".

Alternatively, firms can radically change their capabilities in order to meet completely different client requirements (innovative learning, radical learning). A SKIN firm agent under serious pressure and in danger of becoming bankrupt, will turn to more radical measures, by exploring a completely different area of market opportunities. In the model, an agent under financial pressure turns to a new innovation hypothesis after first "inventing" a new capability for its kene. This is done by randomly replacing a capability in the kene with a new one and then generating a new innovation hypothesis.

According to the Organizational Learning theoretical framework, firms may be also active on the double-loop learning level of the model. They can:

- forget their capabilities (clean up their knowledge space),

- decide on their individual learning strategies themselves (e.g. incremental or radical learning), constructing and changing the strategies according to their past experience and current context. The context consists of external factors such as the actions of clients, competitors and partners and the availability of technical options, and internal factors such as their capital stock and the competencies available to them, and

- engage in networking and partnerships to absorb and exploit external knowledge sources, to imitate and emulate, and to use synergy effects (participative learning).

An agent in the model may consider partnerships (alliances, joint ventures etc.) in order to exploit external knowledge sources. The decision whether and with whom to co-operate is based on the mutual observations of the firms, which estimate the chances and requirements coming from competitors, possible and past partners, and clients. Bolton, Katoka and Ockenfels (2005), writing from a theoretical viewpoint, and Mitchelet (1992), using empirical evidence, both show that greater mutual information, where firms know their partner's history of co-operation, improves the conditions for co-operation. In the SKIN model, a marketing feature provides the information that a firm can gather about other agents: to advertise its product, a firm publishes the capabilities used in its innovation 
hypothesis. Those capabilities not included in its innovation hypothesis and thus in its product are not visible externally and cannot be used to select the firm as a partner. The firm's 'advertisement' is then the basis for decisions by other firms to form or reject cooperative arrangements.

In experimenting with the model, we can choose between two different partner search strategies (Powell et al. 2005), both of which compare the firm's own capabilities as used in its innovation hypothesis and the possible partner's capabilities as seen in its advertisement. Applying the conservative strategy, a firm will be attracted to a partner that has similar capabilities; using a progressive strategy the attraction is based on the difference between the capability sets.

Previously good experience with former contacts generally augurs well for renewing a partnership. For example, Garcia's et al. findings concerning the interaction patterns between public research centres and industrial firms confirm that "prior formal relationships are a fundamental element for collaboration... Strong ties (past relationships) appear to be more fundamental in building university-industry ties" (Garcia et al. forthcoming a: 2f). This is mirrored in the model: to find a partner, the firm will look at previous partners first, then at its suppliers, customers and finally at all others. If there is a firm sufficiently attractive according to the chosen search strategy (i.e. with attractiveness above the 'attractiveness threshold'), it will stop its search and offer a partnership. If the potential partner wishes to return the partnership offer, the partnership is set up.

The model assumes that partners learn only about the knowledge being actively used by the other agent. Thus, to learn from a partner, a firm will add the triples of the partner's innovation hypothesis to its own. For capabilities that are new to it, the expertise levels of the triples taken from the partner are reduced in order to mirror the difficulty of integrating external knowledge as stated in empirical learning research (cf. Cohen and Levinthal 1989, Cantner and Pyka 1998). For partner's capabilities that are already known to it, if the partner has a higher expertise level, the firm will drop its own triple in favour of the partner's one; if the expertise level of a similar triple is lower, the firm will stick to its own version. Once the knowledge transfer has been completed, each firm continues to produce its own product, possibly with greater expertise as a result of acquiring skills from its partner.

If the firm's last innovation was successful, i.e. the value of its profit in the previous round was above a threshold, and the firm has some partners at hand, it can initiate the formation of a network. This can increase its profits because the network will try to create innovations as an autonomous agent in addition to those created by its members and will distribute any rewards back to its members who, in the meantime, can continue with their own attempts, thus providing a double chance for profits. Networks are "normal" agents, i.e. they get the same amount of initial capital as other firms and can engage in all the activities available to other firms. The kene of a network is the union of the triples from the innovation hypotheses of all its participants. If a network is successful it will distribute any earnings above the amount of the initial capital to its members; if it fails and becomes bankrupt, it will be dissolved. 


\subsubsection{Start-ups}

If a sector is successful, new firms will be attracted into it representing Schumpeterian competition by imitation. This is modelled by adding a new firm to the population when any existing firm makes a substantial profit. The new firm is a clone of the successful firm, but with its kene triples restricted to those in the successful firm's advertisement and these having a low expertise level. This models a new firm copying the characteristics of those seen to be successful in the market. As with all firms, the kene may also be restricted because the initial capital of a start-up is limited and may not be sufficient to support the copying of the whole of the successful firm's innovation hypothesis.

\subsubsection{Additional features for modelling university-industry links with SKIN}

\subsubsection{University agents and spin-off companies}

Extending the original model described above, we conceptualised a new agent type: the university agents. Like the firm agents, university agents in the extended SKIN model have an individual knowledge base (kene). Since the university agents have significant technological capabilities, abilities, and expertise, their kenes are twice as long as those of the firm agents. "The importance of the traditional university is well documented in the literature. Their primary mission is to engage in research and disseminate knowledge (...), these universities not only provide a source of technical expertise..., but ... also acquire a wealth of codified and tacit knowledge" (O'Shea et al. 2005: 994f). For this reason, the kene of a university would be expected to be many times larger than those of firms. However, as partners in science-industry networks, only parts of universities (research units, faculties etc.) are involved. University agents do research, form R\&D partnerships with firms (for the sake of simplicity in this model universities do not link with each other), and participate in larger networks.

If a university agent is successful (see below), it breeds a firm (university spin-off) (O'Shea et al. 2005). This is an enterprise that can buy, sell and produce. A spin-off's kene is a clone of the university's innovation hypothesis. If a spin-off is created, a university loses one triple of its kene and gets a new random one (to represent the turnover of researchers); all expertise levels of the spin-off are reduced by one unit.

Unlike the firm agents, university agents in the extended SKIN model are non-profit organisations (they do not produce for the market, they do not sell) with stable public core funding. Their success is measured by the economic gains of their firm partners.

\subsubsection{New parameters for comparing two scenarios}

For our experiments, we created and compared two scenarios: one with and the other without university agents. We were interested in the difference this makes to the firm agents (Cohen et al. 2002, Laursen and Salter 2004). A few new parameters had to be added: to measure the amount of knowledge $k$ of firm agents, we used a term calculated from a firm's kene: its capabilities, abilities (A) and expertise levels (E): 


$$
k_{i}=\sqrt{\sum_{j \in\{\text { capabilities }\}_{i}} A_{i, j} E_{i, j}}
$$

The square root is used here to get values for $k_{i}$ similar to those of the abilities and expertise levels in the same range.

From this, the average knowledge per firm can be derived as

$$
\bar{k}=\frac{1}{n \text { Firms }} \sum_{i \in\{\text { Firms }\}} k_{i}
$$

and the deviation of knowledge among the firms is

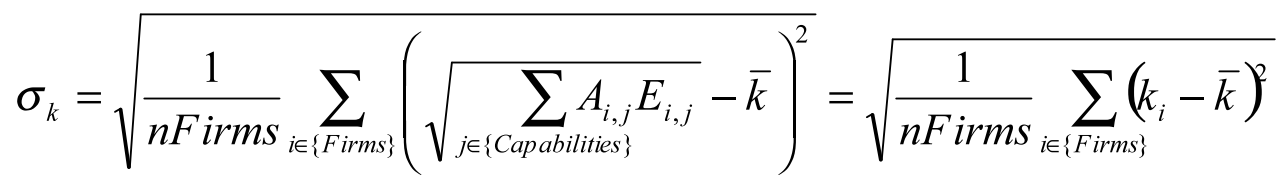

Using these parameters, we can model knowledge flows. The knowledge flow $(k f)$ is the sum of the knowledge increase of firm agents due to their learning from partners. Let $k_{i}{ }^{t-1}$ be the knowledge of a firm agent before learning from partners and $k_{i}^{t}$ be the knowledge of a firm after learning from partners. We can calculate the knowledge flow as

$$
k f=\sum_{i \in \text { partnering Firms }}\left(k_{i}^{t}-k_{i}^{t-1}\right)
$$

To measure the average attractiveness of firms in terms of their potential for R\&D partnerships, we compare the average number of partners between two groups of firms: one group of firms which has links with universities and another of firms that do not cooperate with universities. As an additional success measure, we measure the average lifetime (in time steps) of all firms during a run.

To complete the description of the model and in order to illustrate the career of an individual actor we show the development of its knowledge and capital stock (fig.3) as well as the distribution of its economic transactions over time (fig. 4) in a scenario with universities. The development of the firm's capital stock (bold line in fig 3 ) shows that it performs rather well and is able to increase its capital stock considerably. The spikes in the development of its knowledge (thin line in fig. 3) illustrates that this firm is able to integrate external knowledge stemming from collaborations. At time steps around 10 and 100, the firm is applying external knowledge for only a few periods but this nevertheless has a positive impact on its sales figures. The external knowledge integrated around time step 200 is retained for a longer period and leads to a sustained higher capital stock. 


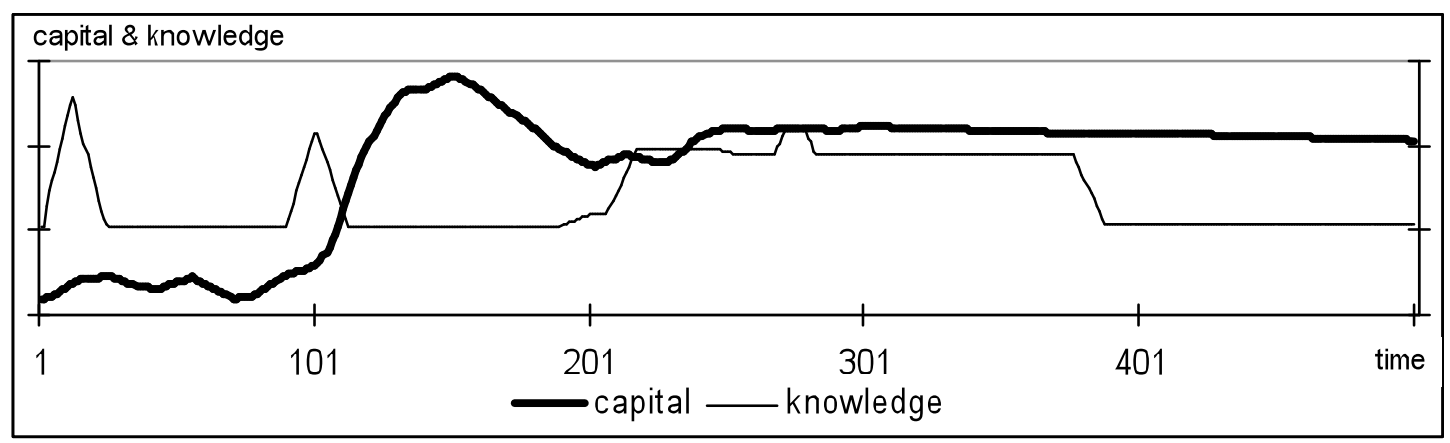

Fig. 3: The development of a selected firm's knowledge and capital stock

The economic effects of the successful integration of external knowledge can be seen in the histogram of fig. 4, which displays the frequency of this firm's economic transactions. Its innovative output generates a high volume of economic transactions and these are responsible for its economic success.

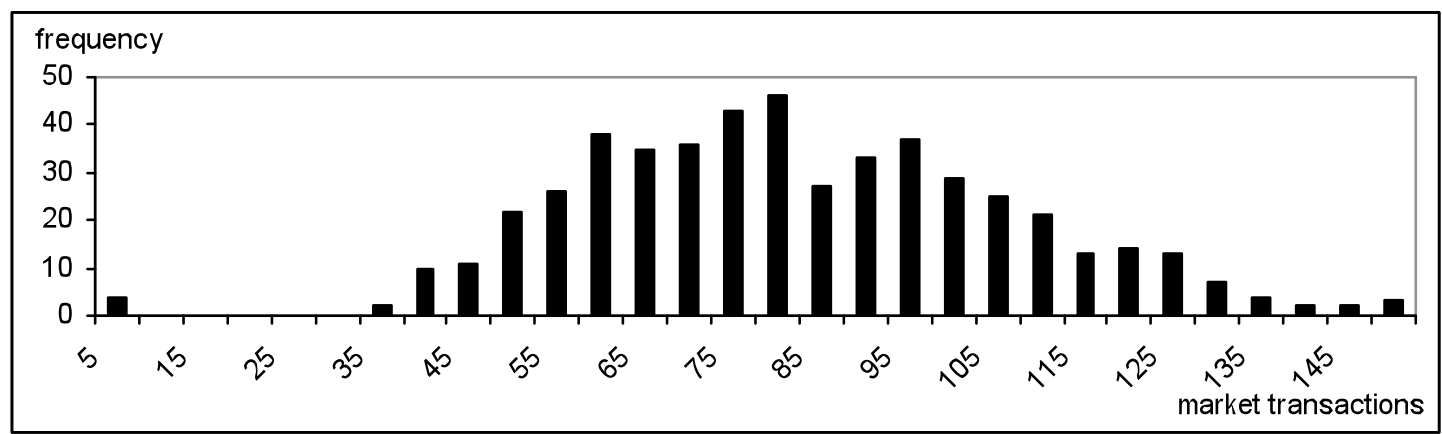

Fig. 4: Market transactions of a selected firm

These plots are only illustrative as individual development paths differ considerably between firms. We are primarily interested in the dynamics of the population as a whole and therefore in the following sections examine in detail the overall behaviour of the agentbased model.

\subsection{Hypotheses}

Using the extended version of the SKIN model introduced above, we can return to our research question: what role do university-industry links play in innovation generation and diffusion? We focus on R\&D co-operations between universities and industry. These partnerships transfer technology from academic institutions to companies and so spread knowledge through the population (Druilhe and Garnsey 2004). Knowledge-intensive industries such as ICT and biotechnology-based pharmaceuticals are well represented in this activity (e.g. Smith and Ho 2006).

Quintas et al. (1992) tell us that the most important factors where a university connection adds value to companies are direct access to sources of cutting-edge scientific knowledge and innovation, and material resources such as university libraries and laboratories. For the firms, university affiliation reduces the costs of developing technological capabilities (George et al. 2002). Especially in knowledge-intensive industries such as ICT and biotech, the speed of 
change is so accelerated that firms can only survive when they have quick access to external technological capabilities (Aslani and Negassi 2006). Universities can therefore provide firstmover advantages for accessing emerging technologies (MacLachlan 1995) and can improve the R\&D flexibility of firms. Fier and Pyka (2009) show that in science-based industries there is also an important knowledge flow from industry to academia because the borderlines between basic and applied research are more or less dissolved.

There are some empirical studies investigating the knowledge flows from universities to firms (Agrawal and Henderson 2002, Siegel et al. 2003). The success and failure of technology transfer activities have also been studied (Henderson et al. 1998, Thursby and Kemp 2002, Chapple et al. 2005). However, most of these studies report measuring difficulties due to the un-observable nature and non-linear properties of knowledge flows. This is the advantage of using an agent-based model: although our hypotheses focus on the un-observable knowledge flows in university-industry networks to which this body of literature refers, we can observe simulated knowledge flows in the model.

O'Shea et al. (2005) report that there might be a relatively direct relationship between university-induced knowledge flows and economic success: "there is a body of empirical research that supports the view that increased university-industry ties and closer partnerships with industry result in greater levels of commercialization" (O'Shea et al. 2005: 997). From this literature, we get the propositions:

- H1: Firms that interact with universities develop more products and have more commercial success

However, O'Shea et al. and others (Cohen et al. 1998, Mansfield and Lee 1996, Branscomb et al. 1999, Hague and Oakley 2000) also point out that, "across national economies there is a need for more emphasis to be placed on transferring and commercialising knowledge generated within universities. More specifically, there is a growing need for universities to disseminate the knowledge generated beyond the narrow confines of the academic community itself" (O'Shea et al. 2005: 995).

- H2: Having universities among the co-operating actors raises the knowledge/competence level of the whole population

- H2.1: we see more variety at the knowledge level

- H2.2: we see increased innovation performance overall

- H2.3: we see increased diffusion in terms of quantity and speed

- H3: Firms interacting with universities will be more attractive to other firms when new partnerships (commercialising, financing, R\&D collaboration with other firms) are considered

- H4: Firms interacting with universities can better adapt to changing environmental conditions

Because of our interest in innovation diffusion in networks, we especially focus on $\mathrm{H} 2$ and its sub-hypotheses. 


\subsection{Experiments ${ }^{4}$}

\subsubsection{Operationalising the hypotheses}

To get reliable results from our experiments, we used 50 runs (1-25 with and 26-50 without university agents). For testing the hypotheses above, the following indicators were measured:

For H1:

- For each firm agent, we measure the time in co-operation with a university agent, and the time since its last co-operation with a university agent

- We measure the average numbers of products brought to market for firm agents depending on the steps in and/or since the last co-operation with a university agent

For $\mathrm{H} 2$ :

- H2.1 variety of knowledge:

O This is the knowledge variance of all firms, calculated according to equation 4 (sig_knowl)

- H2.2 increase of innovation performance:

- We compare a model with university agents to a model without university agents in terms of success (number of innovations)

- H2.3 knowledge diffusion

- We use an adjacency matrix that contains the knowledge flow for each cooperation

For $\mathrm{H} 3$ :

We compare the number of partners of firms co-operating with universities with the number of partners of firms not co-operating with universities

For H4:

- We compare the two possible model variants in terms of the lifetime of the firms (average-age-at-death)

\footnotetext{
${ }^{4}$ We gratefully acknowledge the work of Cedrick Ansorge and Hannes Brauckmann of the Dublin NEMO team who added the necessary features to the SKIN model and conducted the experiments. They used a slightly modified version of SKIN3_8 transcribed to the current NetLogo Version 4.0.3.
} 


\subsubsection{Results}

Table 3 summarises the results for the scenario comparison, in terms of the variables mentioned above.

\begin{tabular}{|c|c|c|c|c|c|c|}
\hline & \multirow[t]{2}{*}{ Firms } & \multicolumn{2}{|c|}{ With universities } & \multicolumn{2}{|c|}{$\begin{array}{c}\text { Without } \\
\text { universities }\end{array}$} & \multirow{2}{*}{$\begin{array}{l}\text { Significance } \\
\text { (t-test of } \\
\text { difference of } \\
\text { means) }\end{array}$} \\
\hline & & mean & s.d. & mean & s.d. & \\
\hline & number of innovations (succ) & 8.1 & 2.3 & 6.8 & 1.9 & 0.060 \\
\hline & amount of knowledge (knowl) & 1199 & 199 & 1017 & 151 & $0.003^{*}$ \\
\hline & $\begin{array}{l}\text { number of partners co-operating } \\
\text { with universities }\end{array}$ & 3.0 & 1.3 & - & - & - \\
\hline & $\begin{array}{l}\text { Number of partners not co- } \\
\text { operating with universities }\end{array}$ & 1.2 & 0.7 & 1.4 & 1.1 & 0.338 \\
\hline & average age at death & 159 & 57 & 152 & 66 & 0.730 \\
\hline 0 & knowledge flow (flow_knowl) & 62 & 35 & 27 & 22 & $0.001^{*}$ \\
\hline & knowledge variance (sig_knowl) & 5.0 & 1.0 & 3.6 & 0.7 & $0.000^{*}$ \\
\hline
\end{tabular}

Table 1: Scenario comparison (asterisks indicate effects significant at the $5 \%$ level): values of indicators measured for 25 examples of the scenario with universities and 25 for the scenario without universities.

To compare the two scenarios, we used an independent two-sample t-test with equal sample sizes and unequal variance. Comparisons that are statistically significant are those with values less than 0.05 in the last column of Table 1.

This means for our experiments:

We found no support (no significantly higher innovation performance; cf. (1) in table 1) for $\mathrm{H} 1$, that is, that firms which interact with universities will profit in the long run from developing technological capabilities with lower transaction costs.

In contrast, $\mathrm{H} 2$, i.e. that having universities in the co-operating population of actors will raise the knowledge or competence level of the whole population, is fully confirmed by the experiments. Firms interacting with universities develop more knowledge (cf. (2) of table 1). This results from the increased knowledge flows stemming from university agents (cf. (6) of table 1).

Equally, H2.1 is confirmed by our experiments. We indeed see more variety at the knowledge level. There is a permanent input of diverse knowledge into the system by the universities that leads to an overall higher level of knowledge per firm (7). The wider knowledge base of the universities provides a significantly higher knowledge flow in the runs where they are included. This increases the probability of knowledge flow in a universityfirm partnership.

$\mathrm{H} 2.2$ is not confirmed. There is a slight trend towards higher innovation performance in the scenario with universities, but it is not significant (1). An increased amount of knowledge does 
not automatically lead to increased innovation performance and to economic success (see correlation succ:knowl in figure 6).

This confirms Bhide's (2008) findings: focusing only on new technology generation does not always lead to economic success. Instead, the capacity to exploit cutting-edge research is crucial. What Bhide describes as 'venturesome consumption' is the ability of business and consumers to use technology derived from research effectively.

So, the most significant results remain at the knowledge level: For $\mathrm{H} 2.3$, we can confirm the hypothesis that having universities in the population will increase knowledge diffusion in terms of quantity and speed. There is indeed a significantly higher knowledge flow in the runs with universities.

Saxenian (1994) showed that the special advantage of the Silicon Valley region was the emergence of a new kind of systems behaviour. The innovation dynamic was characterised by the paradox of co-operation between competitors leading to an even higher level and speed of innovation. These findings are supported by our model.

H3 stated that firms interacting with universities will be more attractive to other firms when new partnerships are considered. This is confirmed by our results: the average number of partners for firms co-operating with universities (3) is higher than for firms that do not (4). This can be explained by the observation that university co-operation triggers innovation diffusion (6) directing knowledge flows to the co-operating firm. By this, the firm will achieve a variety of different kenes. Since we use the progressive partner search strategy in these experiments, these firms become more attractive to other firms searching for a partner.

Oliver and Liebeskind (1998) have also found that links with universities foster collaboration with other research organisations. University affiliation can enhance trust and signal legitimacy for co-operation in general: venture capitalists and international collaborators will be more confident because university affiliation signals higher innovative activity. This could relate to higher visibility, to assumed higher quality (Mian 1997) and to assumed higher networking capacity (Hsu 2007) of firms with university co-operations. Bhide (2008) shows that for many startup companies it was especially difficult to get the first customers. Customers were disinclined to risk trading with a newly founded company even if the technology was promising. Having a respected partner with an established reputation in the creation of technology helped to reduce uncertainty. The fact that universities are not financed by fast changing markets also provides stability and helps to establish trust.

For H4, we found no support. Firms interacting with universities cannot adapt any better to changing environmental conditions than their counterparts. The average lifetime of firms interacting with universities is no longer than those that do not (5). This is also confirmed by the result that success is not directly correlated with the firms' amount of knowledge (see fig. 6 correlation succ:knowl).

Figure 5 summarises the main differences between the performance of the firms in the two scenarios, with universities (black bars) and without universities (grey bars). 


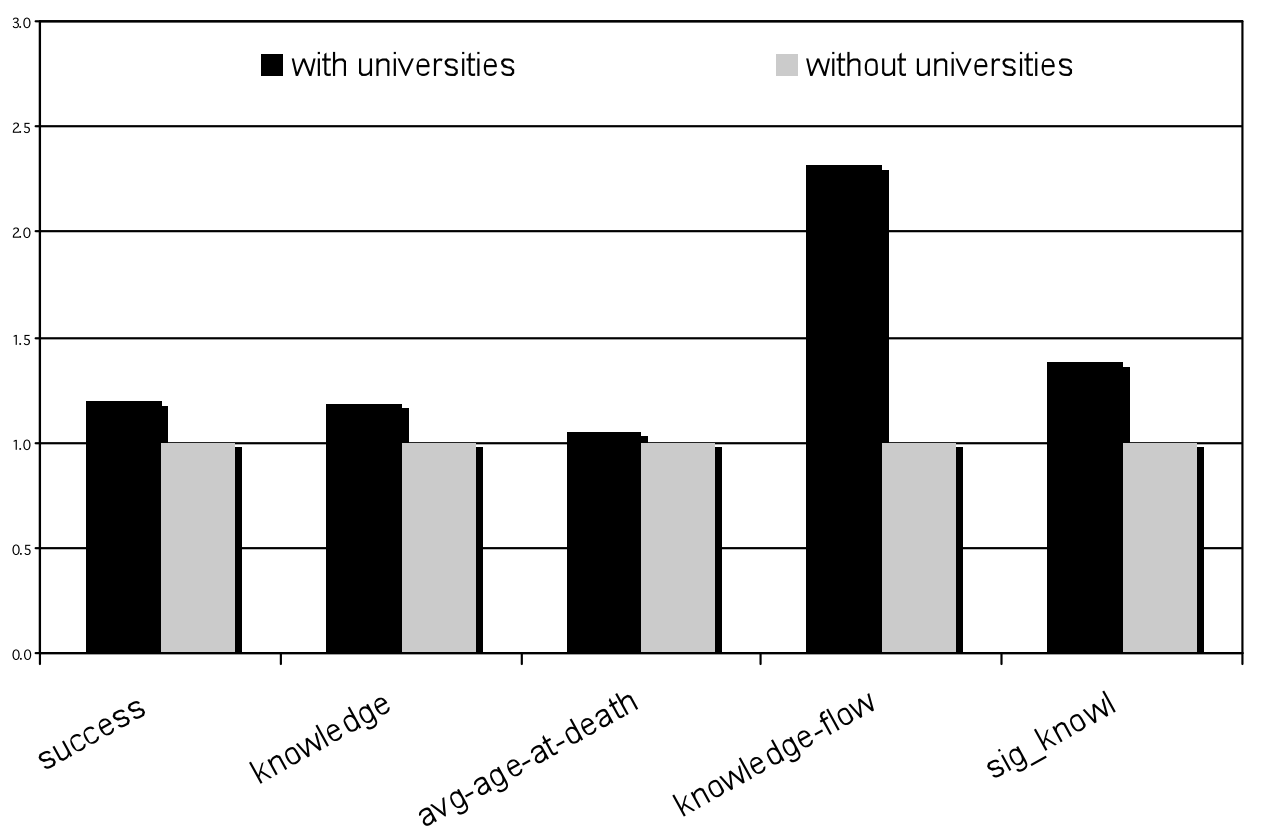

Fig. 5: Scenario comparison (black: with university agents; grey: without university agents)

The main difference between two scenarios concerns the results for innovation diffusion. This can be investigated in more detail by examining the correlations between the indicators shown in Figure 6 for both the scenarios.

The magnitudes of the knowledge flow indicators and their correlations lead to the following observations:

- (succ:flow_knowl) success does not lead to a high knowledge flow, nor vice versa

- (succ:knowl) success and average knowledge per firm are not correlated

- (flow_knowl:knowl) more knowledge per firm leads to increased knowledge flow (i.e. if a higher level of knowledge is provided by universities, this results in an increased knowledge flow and helps to diffuse innovation)

- (succ:firms) a larger population of firms does not automatically create more success

- (sig_knowl:knowl) in the runs with universities, there is a statistically significant correlation between the variance in the quantity of knowledge and the knowledge per firm. 
Figure 6 illustrates these correlations:

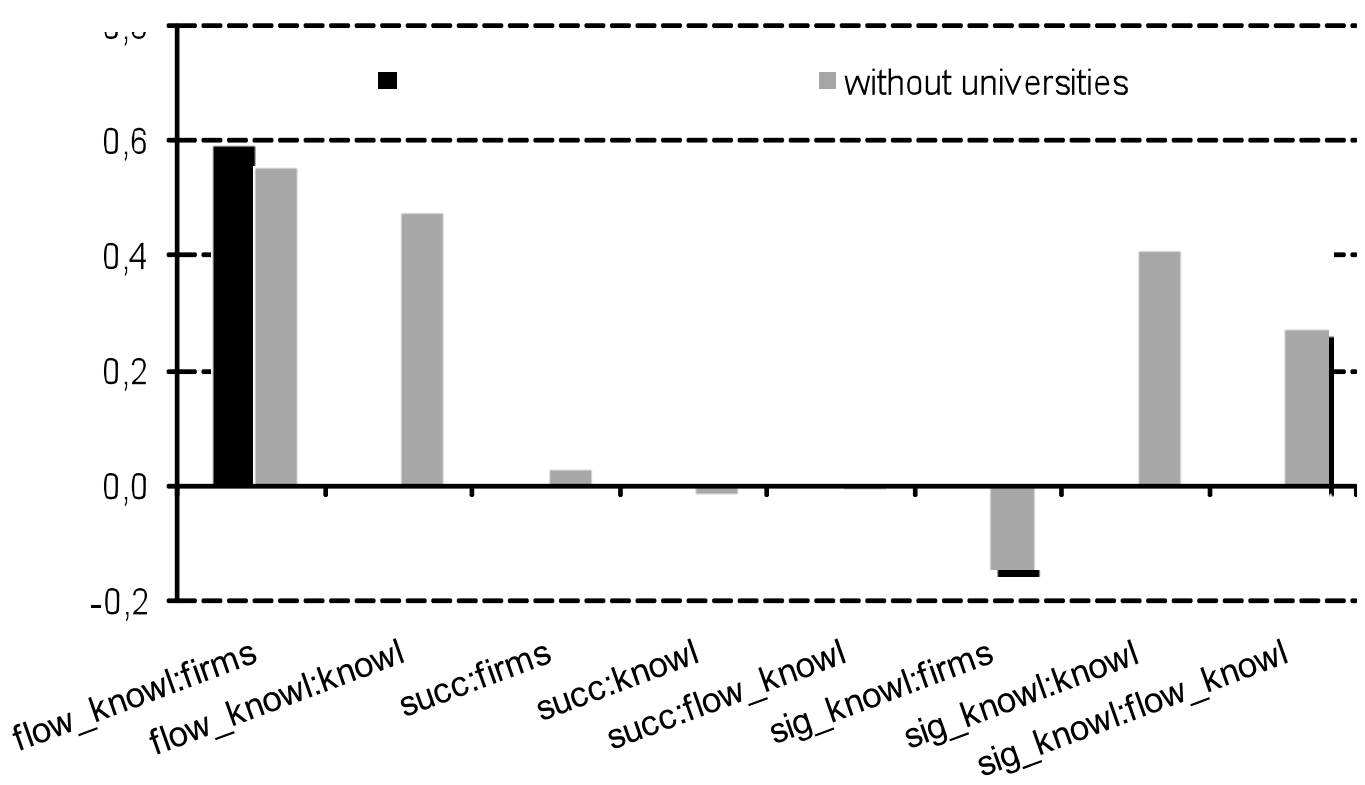

Fig. 6: Correlations relevant for innovation diffusion. Each bar is labelled with the two indicators whose correlation is shown in the bar

The dynamics of the scenario that includes university agents can be depicted as correlated waves of the number of firms, the number of innovations, the quantity of knowledge, and the knowledge flow, as shown in figure 7. 


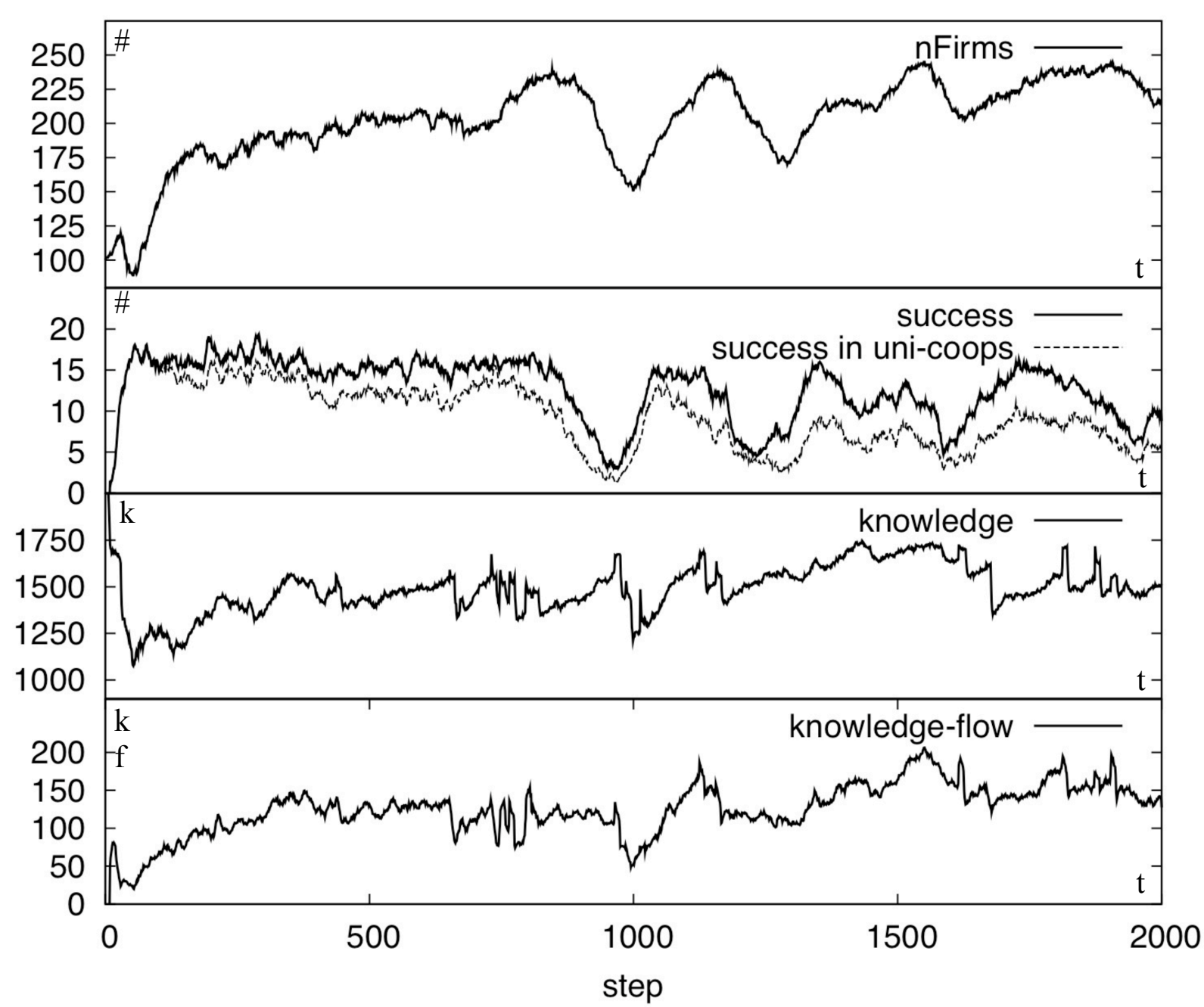

Fig. 7: Example plot of run 10 (10 step running average) (with universities). The topmost graph shows the number of firms; the next the number of successful firms, overall and involved in university collaborations; the next, the total amount of knowledge among the firms (see equation 2); and the bottom graph shows the knowledge flow (the increase in knowledge of firms due to learning from partners, see equation 5).

The number of firms (upper graph in figure 7) grows almost continously during the first 900 time steps. This is the result of imitative entry following the innovation success displayed in the second graph of figure 7 . This graph also shows that throughout the whole simulation the rate of innovation of actors joining an university collaboration is similar to the overall innovation rate. The cyclical ups and downs to be observed in the second half of the simulation stem from a local depletion of technological opportunities and the difficulties that the actors have in exploring new prolific regions in the knowledge space. New discoveries of technological opportunities are accompanied by large increases in the knowledge of actors (third graph in figure 7) and these are mirrored in the growth of knowledge flows (fourth graph in figure 7). The graphs also illustrate how the overall industry dynamics and the degree of competition follows the knowledge dynamics fostered by university-industry linkages. 


\section{Conclusions}

Today innovation activities are undertaken in extremely complex networks, characterised by heterogeneous actors, multi-dimensional interactions and multiple knowledge flows. The increasing complexity creates new challenges for our understanding of the innovation process. In order to understand such multifaceted phenomena as university-industry relationships and to capture their global effect, it is no longer possible to rely solely on traditional methods of analysis. Agent-based modelling instead provides a broader perspective grounded on micro interactions among heterogeneous actors. This methodology explains the emergence of macro dynamics deriving from micro relations, exchanges, and connections among heterogeneous and bounded rational individuals and organisations, thus capturing, in a relatively simple manner, a large part of the complexity of the real world.

Our agent-based model focuses on the knowledge dynamics underlying university-industry relationships. Performing experiments on the simulation provides new insights that potentially contribute to the formation of a more widely accepted perspective on the effects of university-industry relationships.

Experimenting with university-industry links in knowledge-intensive industry scenarios has provided new and promising insights. Our experiments have compared a SKIN population with and without university agents. We can show that there is indeed no linear and immediate relationship between increased knowledge inputs and economic profits - our experiments reproduced the ambiguous evaluations of empirical studies.

Firms interacting with universities cannot adapt to changing environmental conditions any better than their counterparts without university affiliation. The average lifetime of firms interacting with universities is no greater than those that do not. There seems to be a slight trend towards higher innovation performance in the scenario with universities, but it is not significant. Neither does an increased amount of knowledge automatically lead to increased innovation performance and thus to economic success.

However, if we turn from the rather unrealistic assumption of linear relations between knowledge input and economic profit towards investigating the non-linear and self-organising dynamics of innovation networks, we can see the positive effects of university-industry links on innovation diffusion. The potential profitability of university affiliation is still an open issue for firms. Policy can certainly improve the performance of academia's entrepreneurial and other industry reachout activities. However, the simulation results have shown that universityfirm co-operation can contribute effectively to the processes of commercialisation and university technology transfer. Much will depend on how these interaction patterns will actually be implemented and managed (cf. Perkmann and Walsh 2007).

Results show that having co-operating universities raises the knowledge and competence levels of the whole population of actors, increases the variety of knowledge among the firms, and increases innovation diffusion in terms of quantity and speed. Furthermore, firms interacting with universities are more attractive for other firms when new partnerships are considered. Although no direct relation between university contributions and economic success can be found, the agent-based simulation confirms that university-industry links improve innovation diffusion and collaborative arrangements in innovation networks. 
Our results show the important and positive impact that university-industry linkages exert on the overall industry and knowledge dynamics. In particular the spin-off effect on entrepreneurship deserves much more emphasis in the design of policy instruments: in any university-firm co-operation new business opportunities might be detected.

Further development of the model will be needed to recognise the heterogeneity of universities. Adding this will probably help to explain the sometimes contradictory results of university-industry links and may also advance further our understanding of the complex processes of innovation in knowledge-intensive sectors. In this vein the effects of firm size also deserves more detailed analysis: are there systematic differences between large diversified firms and small dedicated technology companies with respect to their cooperation with university actors? These issues are on our agenda for future research. 


\section{References}

Ackermann, R. (1970). The Philosophy of Science, Pegasus, New York.

Agrawal, A. and R. Henderson (2002): Putting patents in context: exploring knowledge transfer from MIT. Management Science 48. 44-60.

Ahrweiler, P., Gilbert, N. and Pyka, A. (2006). Institutions matter, but ... Organisational Alignment in Knowledge-based Industries. Science, Technology and Innovation Studies 2: 3-18.

Ahrweiler, P., S. de Young and P. Windrum (2003). Evaluating innovation networks. In: A. Pyka and G. Kueppers (eds.), Innovation Networks - Theory and Practice, Edward Elgar, Cheltenham: 197-212.

Argyris, C. and D. A. Schoen (1996). Organizational Learning: a theory of action perspective, Addison-Wesley, Reading, MA.

Aslani, A.A. and Negassi, S. (2006). Is technology integration the solution to biotechnology's low research and development productivity? Technovation 26(5-6): 573-582.

Atkinson, A.B. and J.E. Stiglitz, J. E. (1969). A new view on technological change. Economic Journal 79: 116-131.

Bhide, A. (2008). The venture-some economy. Princeton University Press.

Bolton, G.E., Katoka, E. and Ockenfels, A. (2005), Co-Operation among strangers with limite3d information about reputation, Journal of Public Economics, Vol. 89, 1457-1468.

Branscomb, L.M., F. Kodama and R. Florida (1999): Industrializing knowledge: universityindustry links in Japan and the United States. MIT Press, Cambridge.

Brusoni, S., Prencipe A. and K. Pavitt (2001). Knowledge Specialisation, Organizational Coupling and the Boundaries of the Firm: Why Firms Know More Than They Make? Administrative Science Quarterly, 46: 597-621.

Cantner, U. and Pyka, A. (1998). Absorbing Technological Spillovers. Simulations in an Evolutionary Framework. Industrial and Corporate Change 7(2): 369-397.

Castells, M. and P. Hall (1994). Technopoles of the World. The making of the twenty-firstcentury industrial complexes. London.

Chapple, W., A. Lockett, D. Siegel and M. Wright (2005): Assessing the relative performance of U.K. university technology transfer offices: parametric and non-parametric evidence. Research Policy 34: 369-384.

Cohen, W.M. and Levinthal, D. (1989). Innovation and learning: the two faces of R\&D. The Economic Journal 99: 569-596.

Cohen, W. M., Nelson, R. R. and Walsh, J. P. (2002). Links and impacts: The influence of public research on industrial R\&D. Management Science 48(1): 1-23.

Cohen, W.M., R. Florida, L. Randazzese and J. Walsh (1998). Industry and the academy: uneasy partners in the cause of technological advance. In: N. Roger (ed): Challenges to research universities. Washington: 171-199.

Coombs, R. (1988). Technological opportunities and industrial organization. In: G. Dosi et al. (eds.): Technical change and economic theory. London: Pinter Publishers.

Cowan, R., P.A. David and D. Foray (2000). The explicit economics of knowledge: Codification and tacitness. Industrial and Corporate Change 9(2): 211-233. 
Dasgupta, P. and P. Stoneman (1987) (eds.). Economic Policy and Technological Performance. Cambridge University Press, Cambridge, Mass.

De Geus, A. (1997). The Living Company, Brealy, London.

D'Este, P. and P. Patel (2007). University-industry linkages in the UK: what are the factors underlying the variety of interactions with industry? Research Policy 36: 1295-1313.

Dewey, J. (1938). Experience and Education, Collier, New York.

Dosi, G., P. Llerena and M.S. Labini (2006). The relationships between science, technologies and their industrial exploitation: an illustration through the myths and realities of the socalled European Paradox. Research Policy 35: 1450-1464.

Druilhe, C. and E. Garnsey (2004). Do academic spin-outs differ and does it matter? Journal of Technology Transfer 29(3-4): 269-285.

Duncan, R.B. (1974). Modifications in decision structure in adapting to the environment: some implications for organizational learning, Decision Sciences 5: 705-725.

Eliasson, G. (1995). General purpose technologies, industrial competence and economic growth. Working Paper, Royal Institute of Technology, Stockholm.

Etzkowitz, H. (2002): MIT and the rise of entrepreneurial science. Routledge.

Etzkowitz, H. (2004): The evolution of the entrepreneurial university. Int. J. Technology and Globalisation 1(1): 64-77.

Fier, H. and A. Pyka (2009), Against the one-way street: Analyzing knowledge transfer from industry to science, ZEW working paper.

Florida, R. (2000). The role of the university: leveraging talent, not technology. In: A. Teich et al. (eds.): AAAS Science and Technology Policy Yearbook. Washington: 363-373.

Garcia, R., D.T. Dunn and L.A. Smith (forthcoming a). Boundary spanners and social networks surrounding research centers. NSF 04-556 Partners for Innovation Program. Working Paper.

Garcia, R., D.T. Dunn and L.A. Smith (forthcoming b). Performance of knowledge interactions between public research centres and industrial firms: an application for Spanish public research centres based on project-level data. Working Paper.

George, G., S.A. Zahra and D.R. Wood (2002). The effects of business-university alliances on innovative output and financial performance: A study of publicly traded biotechnology companies. Journal of Business Venturing 17(6): 577-609.

Geroski, P.A. (1995). Do spillovers undermine the incentives to innovate? In: Dowrick, S. (ed.): Economic Approaches to Innovation. Cheltenham, UK: Edward Elgar.

Gilbert, N. (2007). Agent-based models. Sage Publications. London.

Gilbert, N. and K. Troitzsch (2005). Simulation for the Social Scientist. 2nd edition. Berkshire, UK: Open University Press.

Gilbert, G. N. (1997). A Simulation of the Structure of Academic Science. In: Sociological Research Online 2(2). http://www.socresonline.org.uk/socresonline/2/2/3.html.

Gilbert, N., A. Pyka and P. Ahrweiler (2003). Simulating innovation networks. In: A. Pyka and G. Kueppers (eds.), Innovation Networks - Theory and Practice, Edward Elgar, Cheltenham: 169-196.

Gilbert, N., P. Ahrweiler and A. Pyka (2007). Learning in innovation networks: some simulation experiments. Physica A 378: 100-109. 
Hague, D. and K. Oakley (2000). Spinoff and start-ups in UK universities. Committee of ViceChancellors and Principals Report, London.

Hanusch, H. and A. Pyka (2007). The Principles of Neo-Schumpeterian Economics. Cambridge Journal of Economics 31(2): 275-289.

Harrigan, K. (1985). Strategies for Joint Ventures. Lexington: Lexington Books.

Hedberg, B. (1981). B. Hedberg, How organizations learn and unlearn, in P. C. Nystrom and W. H. Starbuck, eds., Handbook of Organizational Design, Oxford University Press, Oxford.

Henderson, R., Jaffe, A. And Trajtenberg, M. (1998). Universities as a source of commercial technology: a detailed analysis of university patenting, 1965-1988. Review of Economics and Statistics 80/1: 119-127.

Hsu, D.H. (2007). Experienced entrepreneurial founders, organizational capital, and venture capital funding. Research Policy 36: 722-741.

Jordan, D. and O'Leary, E. (2007). Is Irish Innovation Policy Working? Evidence from HighTechnology Businesses. Journal of Statistical and Social Inquiry Society of Ireland. October, 2007.

Knight, F.H. (1921), Risk, Uncertainty and Profit. Chicago.

Laursen, K. and A. Salter (2004). Seaching how and low: what types of firms use universities as source of innovation? Research Policy 33: 1201-1215.

Lee, Y. (1996). "Technology transfer" and the research university: a search for the boundaries of university-industry collaboration. Research Policy 25: 843-863.

Levin, R.C. and P. C. Reiss (1988). Cost-reducing and demand creating R\&D with spillovers. Rand Journal of Economics 19: 538-556.

MacLachlan, A. (1995). Trusting outsiders to do your research: How does industry learn to do it? Research and Technology Management 38(6): 48-53.

Malerba, F. and L. Orsenigo (1993). Technological regimes and firm behaviour. Industrial and Corporate Change 2: 45-71.

Mansfield, E. and Y. Lee (1996). The modern university: contributor to industrial innovation and recipient of industrial R\&D support. Research Policy 25: 1027-1058.

Meyer, M. (2003). Academic entrepreneurs or entrepreneurial academics? Research-based ventures and public support mechanism. R\&D Management 33: 107-115.

Meyer-Krahmer, F. and U. Schmoch (1998): Science-based technologies: university-industry interactions in four fields. Research Policy 27: 835-851.

Mian, S.A. (1997). Assessing and managing the university technology business incubator: an integrative framework. Journal of Business Venturing 12: 251-285.

Michael, D.M. (1973). On learning to plan and planning to learn, Jossey-Bass, Hoboken, NJ.

Michelet, R. (1992), Forming successful strategic marketing alliances in Europe, Journal of European Business, Vol. 4, 11-15.

Nelson, R.R. (1988). Modelling the connections in the cross section between technical progress and R\&D intensity. Rand Journal of Economics 19: 478-485.

Nelson, R.R. (1989). What is private and what is public about technology. Science, Technology and Human Values 14: 229-241.

O' Shea, R.P, H. Chugh, H. and T.J. Allen (2008). Determinants and consequences of university spin-off activity: A conceptual framework. Journal of Technology Transfer, forthcoming. 
O'Shea, R., T. Allen, A. Chevalier and F. Roche (2005): Entrepreneurial orientation, technology transfer and spin-off performance of U.S. universities. Research Policy 34: 9941009.

Oliver, A.L. and J.P. Liebeskind (1998). Three levels of networking for sourcing intellectual capital in biotechnology: Implications for studying inter organizational networks. International Studies of Management and Organization 27: 76-103.

Pavitt, K. (1987). The objectives of technology policy. Science and Public Policy 14: 182-188 (reprinted in Pavitt, K. (1999). Technology, Management and Systems of Innovation, Edward Elgar, Cheltenham.

Perkmann, M. and K. Walsh (2007). University-industry relationships and open innovation: towards a research agenda. International Journal of Management Reviews 9: 259-280.

Polanyi, M. (1967). Personal Knowledge: Towards a Post-Critical Philosophy, N.Y., Harper Torchbook.

Powell W.W., D.R. White, K.W. Koput and J. Owen-Smith (2005). Network Dynamics and Field Evolution: The Growth of Inter-organizational Collaboration in the Life Sciences. American Journal of Sociology 110: 1132-1205.

Pyka, A., N. Gilbert and P. Ahrweiler (2007). Simulating knowledge generation and distribution processes in innovation collaborations and networks. Cybernetics and Systems 38: 667-693.

Pyka, A. and G. Kueppers, G. (2003) (eds.), Innovation Networks - Theory and Practice, Edward Elgar, Cheltenham.

Pyka, A. and P.P. Saviotti (2003). Innovation Networks in the Biotechnology-based Industries, in: A. Pyka and G. Kueppers (eds.), Innovation Networks - Theory and Practice, Edward Elgar, Cheltenham: 75-107.

Pyka, A. and P.P. Saviotti (2005). The Evolution of R\&D Networking in the Biotech Industries. International Journal of Entrepreneurship and Innovation Management 5(1/2): 49-68.

Pyka, A. and M. Hörlesberger (2004). A neurological view on the technological brain of a firm, Austrian Research Centers, mimeo.

Romer, P. (1990). Endogenous Technical Change. Journal of Political Economy 98: 71-102.

Sapienza, A. (1989). R\&D collaboration as a global competitive tactic: biotechnology and the ethical pharmaceutical industry. R\&D Management 19(4): 285-295.

Saxenian, A. (1994). Regional Advantage: Culture and Competition in Silicon Valley and Route 128, Harvard University Press, Cambridge.

Schartinger, D., C. Rammer, M. Fischer and J. Froehlich (2002). Knowledge interactions between universities and industry in Austria: sectoral patterns and determinants. Research Policy 31: 303-328.

Schmoch, U., F. Laville, P. Patel and R. Frietsch (2003). Linking technological areas to industrial sectors, Final Report to the European Commission, DG Research.

Shrader and Siegel (2007). Assessing the relationship between human capital and firm performance: evidence from technology-based new ventures, Entrepreneurship: Theory and Practice, Nov. 2007

Siegel, D. S., D. Waldman, L. Atwater and A.N. Link (2003). Commercial knowledge transfers from universities to firms: improving the effectiveness of university-industry collaboration. Journal of High Technology Management Research 14: 111-133. 
Slaughter, S. and L. Leslie (1999). Academic capitalism: Politics, policies, and the entrepreneurial university. Baltimore: Johns Hokpins.

Smith, H.L. and K. Ho (2006). Measuring the performance of Oxford University, Oxford Brookes University and the government laboratories' spin-off companies. Research Policy 35: 1554-1568.

Teece, D. (1987). Capturing Value from a Technological Innovation, in: B.R. Guile et al. (eds.): Technology and Global Industry, National Academic Press, Washington.

Tesfatsion, L. (2001). Agent-based modelling of evolutionary economic systems. IEEE Transactions on Evolutionary Computation 5: 1-6.

Thursby, J. and S. Kemp (2002): Growth and productive efficiency of university intellectual property licensing. Research Policy 31: 109-124.

Toulmin, S. (1967). The Philosophy of Science: an introduction, Hutchinson, London.

Vaux, J. and N. Gilbert (2003). Innovation networks by design: the case of mobile VCE. In: A. Pyka and G. Kueppers (eds.), Innovation Networks - Theory and Practice, Edward Elgar, Cheltenham: 55-74.

Weber, M. (2003). Innovation networks and the transformation of large socio-technical systems: the case of combined heat and power technology. In: A. Pyka and G. Kueppers (eds.), Innovation Networks - Theory and Practice, Edward Elgar, Cheltenham: 133-165.

Windrum, P. (2003). The role of knowledge-intensive business services (KIBS) in ecommerce. In: A. Pyka and G. Kueppers (eds.), Innovation Networks - Theory and Practice, Edward Elgar, Cheltenham: 108-132.

Windrum, P. (2007). Neo-Schumpeterian simulation models. In: H. Hanusch and A. Pyka (eds.): Elgar Companion to Neo-Schumpeterian Economics. Cheltenham, UK: Edward Elgar.

Winter, S.G. (1984). Schumpeterian Competition in alternative Technological Regimes, Journal of Economic Behaviour and Organization 5: 237-261.

Wright, M., A. Vohera and A. Lockett (2004). The formation of high-tech university spinouts: the role of joint ventures and venture capital investors. Journal of Technology Transfer 29: 287-310.

Wright, M., A. Locket, B. Clarysse and M. Binks (2006). University spin-out companies and venture capital. Research Policy 35: 481-501. 